\title{
DISTRIBUTION OF RESPIRATORY GASES IN A CLOSED BREATHING CIRCUIT. I. IN NORMAL SUBJECTS
}

\author{
By H. C. A. LASSEN, A. COURNAND AND D. W. RICHARDS, JR. \\ (From the Department of Medicine, College of Physicians and Surgeons, Columbia University, \\ and the Presbyterian Hospital, New York City)
}

(Received for publication August 11, 1936)

A closed breathing circuit of small volume, similar to that described by Figure 1, has been extensively used in recent years (Van Slyke and Binger (1), Anthony (2), Christie (3), Sendroy, Hiller and Van Slyke (4)), particularly for the determination of residual lung volumes. ${ }^{1}$

It has been generally assumed (1), that after a preliminary period of several minutes of quiet breathing, during which redistribution of gases between lungs and spirometer takes place, the concentration of any inert gas then becomes equal throughout the various parts of the system, and

1 The terminology employed in these papers is that given by Christie. By "functional residual air" is meant the volume of air remaining in the lungs at the end of a normal quiet expiration. thereafter remains equally distributed (except for a constant slight excess concentration of inert gases in the lungs, so long as the R.Q. is less than 1). The concentration of all inert gases would, of course, gradually increase in the system as the total volume of the system diminishes due to $a b-$ sorption of oxygen.

In order to test this assumption, and more generally to obtain some further information as to the distribution of respiratory gases in the lungs, we have attempted to follow the progressive changes in inspired and expired air gases, during the course of quiet breathing over a period of several minutes in a small closed breathing circuit.

The apparatus, described in Figure 1, is essentially that used by Christie (3) for the determina-

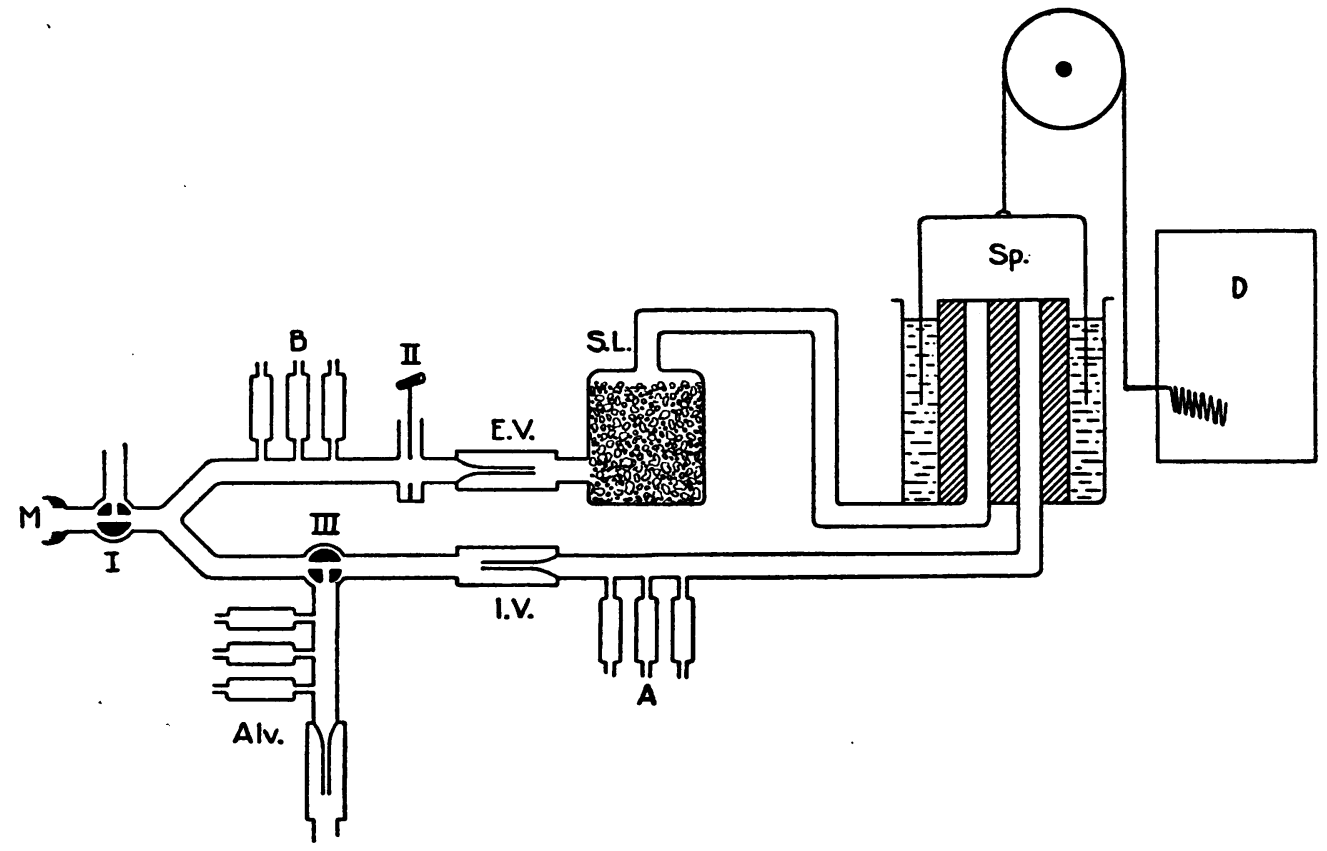

Fig. 1. Diagram of Closed Breathing Circuit.

$\mathrm{M}=$ mouthpiece. I, II, and III = valves (see text). Alv. = "alveolar air" tube. $A, B$ = gas samplers (see text). I. V. = inspiratory flutter valve. E. V. = expiratory flutter valve. Sp. $=$ spirometer. S. L. $=$ soda lime. $D=$ moving drum for graphic record of respiration. 
tion of functional residual air, with certain additions: (a) sets of evacuated gas sampling tubes are attached to the inspiratory tubing (at $A$ ), and to the expiratory tubing (at $B$ ); $(b)$ a side tube leads off from a three-way valve, between inspiratory flutter valve and mouthpiece, for the collection of alveolar air samples; $(c)$ a shut-off valve is interposed between expiratory tube and soda lime bottle. The volume of the dead space of this breathing circuit, as measured by Christie's method, was $1830 \mathrm{cc}$.

The method, briefly stated, was to fill the spirometer with a measured volume of oxygen, to have the subject breathe through the circuit until redistribution of inert gas (nitrogen) between lungs and spirometer was completed; then to take simultaneous samples of inspired and expired air, at successive intervals during this subsequent equilibrium period. Our interest lay in the nature of the equilibrium state existing after the initial redistribution of gases was completed.

The time required for redistribution of inert gases between lungs and spirometer in an apparatus of this kind has been estimated by Van Slyke and Binger (1) to be about 5 minutes. These investigators used a hydrogen-oxygen mixture in the spirometer, and found that at the end of 5 minutes of normal quiet respiration, the $\mathrm{N}_{2} / \mathrm{H}_{2}$ ratio in the spirometer reached a level which thereafter remained essentially constant.

The details of technique in our experiments were as follows. With the subject (usually under basal conditions) attached to the apparatus by mouthpiece and noseclip, and breathing room air through Valve I, samples of alveolar air were first taken by having him make a single forced expiration through Valve III and the side tube, Valve I being turned from room air to apparatus. When respiratory equilibrium was again established (after 3 minutes), Valve I was turned, at the end of a normal expiration, and the subject then breathed for 8 minutes in the closed circuit. During this time oxygen was, of course, being absorbed from the system, and the oxygen concentration was therefore progressively decreasing. The course of respiration and of oxygen consumption was recorded on the drum.

At the end of 6 minutes' breathing, a sample of air was taken, during the course of an expiration, at $A$. This was the air which was to be inhaled at the next following inspiration. The subject was then allowed to take this next inspiration. At the end of the immediately following expiration, an expiratory sample was taken at $B$. Thus, in the $A$ and $B$ samples, as taken, we had essentially the composition of an inspiratory sample of air, and of the last part of the next following expiration.

The $A$ sample would, of course, represent the exact composition of all the inspired air of the next breath, only if the composition of air were constant along the whole inspiratory tube, from spirometer to mouthpiece, and if the volume of inspired air equalled the volume of this inspiratory tubing. The volume of inspiratory tubing was about $420 \mathrm{cc}$; and as the spirometer air differed in $\mathrm{O}_{2}$ and $\mathrm{N}_{2}$ concentrations from air in $A$ samples by only about 0.25 per cent, it is probable that the average value of nitrogen concentration of inspired air differed from the corresponding $A$ sample nitrogen concentration by less than 0.1 per cent.

Similar $A$ and $B$ samples were obtained at the end of 7 minutes' breathing, and at the end of 8 minutes. Immediately upon taking the 8th minute expiratory sample, Valve III was turned, the subject directed to make a forced deep expiration, and an alveolar air sample was taken from the side tube.

The gas samples were analyzed by a Haldane apparatus, provided with a burette graduated between 5.0 and $10.0 \mathrm{cc}$.

Several experiments of this type were run on each of three normal individuals. The results of all were consistent.

The results of a typical experiment, with the normal subject A.C., are given in Table I. The first horizontal row of figures shows the concentrations of gases in the alveolar air sample taken while the subject breathed room air; the " $A$ sample" here represents room air, the " $B$ sample" alveolar air. It will be seen that expired nitrogen concentration is greater than inspired nitrogen concentration, as one would expect.

The next three horizontal rows of figures give the concentrations of gases in inspired $(A)$ and expired $(B)$ samples, at the end of 6,7 and 8 minutes' breathing, in the closed circuit, during which time the oxygen concentration in the system was steadily decreasing, and nitrogen concen- 
TABLE I

Composition of inspired $(A)$ and expired $(B)$ air, with progressively decreasing oxygen in inspired air (closed circuit), Subject A.C., December 3, 1935

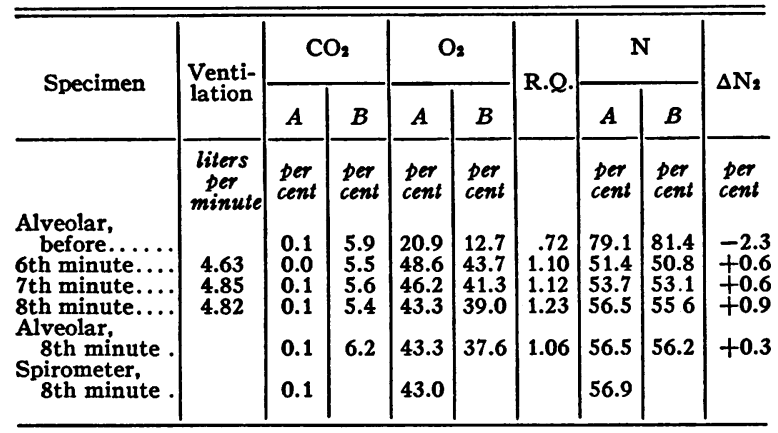

tration increasing. It will be seen that in these samples, expired nitrogen concentration is less than inspired nitrogen concentration. The differences are given in the last column on the right. Associated with this decrease in expired nitrogen concentration is a relative increase in expired oxygen concentration, so that the R.Q. as measured is greater than 1 .

One's first thought in attempting to explain the excess of inspired over expired nitrogen, and the high R.Q., is that the subject was hyperventilating. From other data in the experiment, this seems unlikely: as the expired $\mathrm{CO}_{2}$ values were not low, were in fact near the alveolar $\mathrm{CO}_{2}$ levels ; the alveolar $\mathrm{CO}_{2}$ at the end of the breathing period was not lower than at the beginning; and the total volume of ventilation was low. This question was, however, decided by experiment. Two further sets of breathing experiments were run, on each of two normal subjects, using the same apparatus: one set in which the inspired air was kept constant in composition; and the other in which the inspired air was increasing in its oxygen concentration during the 8 minutes of breathing. The first was arranged by removing the spirometer bell, having the subject inspire room air through the inspiratory $(A)$ tube, and collecting expired air as it issued from the expiratory tubing. The second was carried out by running oxygen into an opening in the expiratory tubing at a constant rate of $500 \mathrm{cc}$. per minute.

In both these two accessory experiments it was found that the nitrogen concentrations of the expired air samples were regularly greater than those of the inspired air.

Figure 2 shows the results of the three sets of experiments. In the first, with progressively decreasing inspired oxygen, expired nitrogen concentration is less than inspired nitrogen concen-

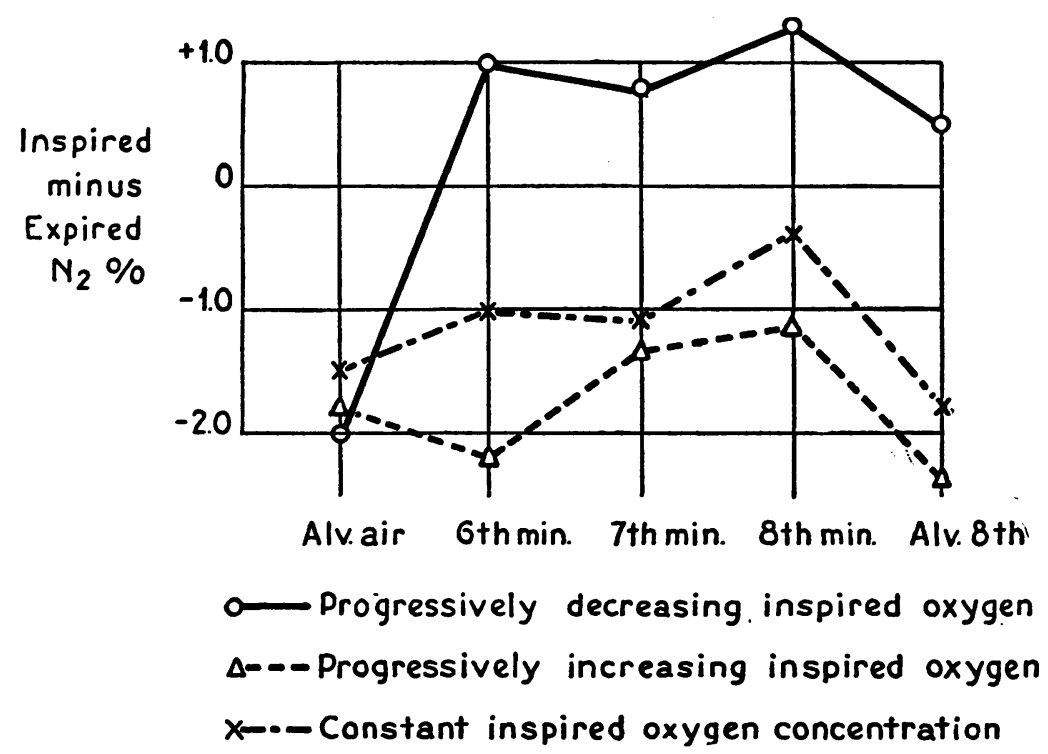

Fig. 2. Difference between Inspired and Expired Air Nitrogen Concentrations $\left[\Delta \mathrm{N}_{2}(\mathrm{I}-\mathrm{E})\right]$.

Normal subject. For explanation see text. 
tration; in the other two, with constant or increasing inspired oxygen, expired nitrogen is the greater. The alveolar air sample taken at the end of the 8th minute shows a similar effect, though in the decreasing oxygen experiment the nitrogen deficit is less marked. Some of this relative increase in expired nitrogen in the alveolar samples is due to the extra time (about 5 seconds) required for a complete forced expiration, with further concentration of nitrogen in the lungs in this interval.

The true explanation of this qualitative shift in nitrogen concentrations, in the decreasing oxygen system, is not difficult. If one has a volume of 1 liter of a gas mixture of 50 per cent oxygen and 50 per cent nitrogen, then adds to this liter a volume of $200 \mathrm{cc}$. of 45 per cent oxygen and 55 per cent nitrogen, the resulting concentrations of gases in the whole $1200 \mathrm{cc}$., after mixture, will be approximately 51 per cent nitrogen and 49 per cent oxygen (Figure 3 ). A mixed sample removed will, of course, have the same concentration.

In the same manner the lungs are a storehouse, as it were, of earlier breaths, all of which in this

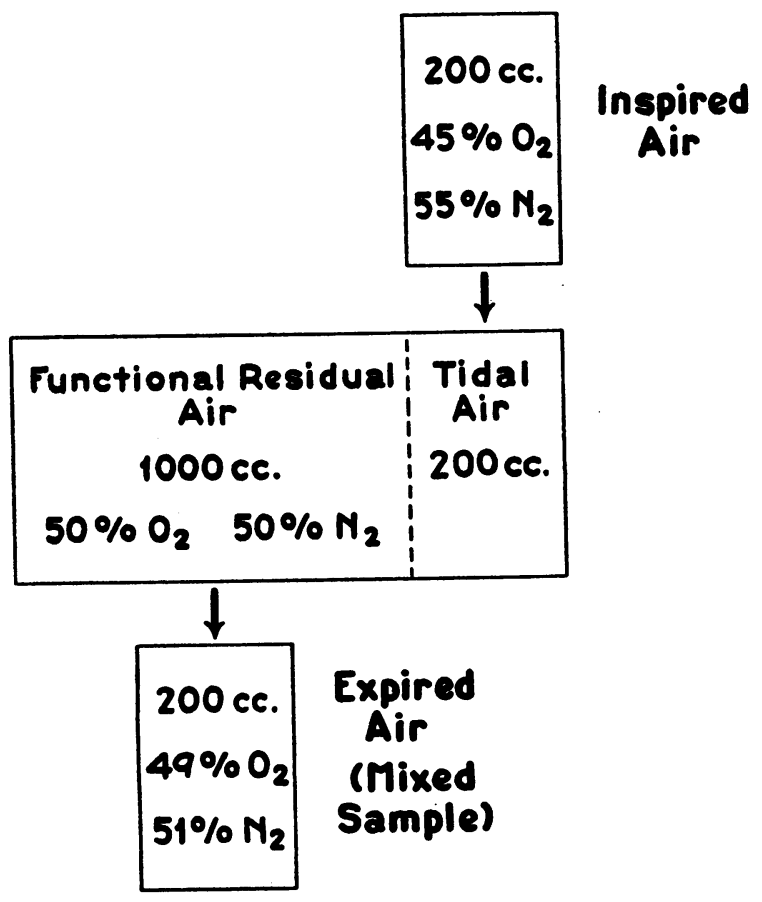

Fig. 3. Diagram of Mixing, with Decreasing INSPIRED OXYGEN. instance have had higher oxygen and lower nitrogen concentrations than in the immediately preceding inspired sample.

Granting the above principle, one must next inquire whether in the actual breathing circuit which we have employed, the "oxygen storage effect" will be quantitatively sufficient to explain the experimentally found excess of inspired over expired nitrogen concentrations.

If we take figures from a group of experiments performed with normal subjects we find that the average change in composition of inspired air per breath is -0.25 per cent for oxygen and +0.25 per cent for nitrogen. Other average measurements, obtained experimentally, of lung volumes, ventilation, and composition of alveolar air, are as follows :

Functional residual air ............ 2160 cc.

Tidal air (inspired) $\ldots \ldots \ldots \ldots \ldots \ldots, 495$ cc.

Tidal air (expired) $\ldots \ldots \ldots \ldots \ldots \ldots \ldots, 490$ cc.

Alveolar $\mathrm{CO}_{2} \ldots \ldots \ldots \ldots \ldots \ldots \ldots \ldots, 5.50$ per cent

Respiratory dead space (approximate) 100 cc.

Respiratory quotient $\ldots . \ldots \ldots \ldots \ldots \ldots, 0.81$

$\mathrm{CO}_{2}$ excreted per breath .............. 21.5 cc.

$\mathrm{O}_{2}$ absorbed per breath $\ldots \ldots \ldots \ldots \ldots, 26.5$ cc.

Respiratory rate, per minute ......... 10

Using these figures we wish to calculate the gaseous composition of a series of expired breaths; as successive inspired breaths are inhaled, mixed with existing pulmonary air, and again exhaled; each inspired breath containing 0.25 per cent more $\mathrm{N}_{2}$ than its predecessor.

For convenience we will arbitrarily choose, as a starting point, a condition of the breathing circuit in which nitrogen is equal in lungs and spirometer. Suppose the concentration of nitrogen to be 50 per cent in spirometer, and 50 per cent in lungs, at the end of an inspiration; the alveolar $\mathrm{CO}_{2} 5.50$ per cent, and alveolar oxygen 44.50 per cent.

As expiration is carried out, 490 cc. are exhaled. The first $100 \mathrm{cc}$. (dead space) contain unchanged inspired air; the remaining 390 cc. contain: 5.50 per cent $\times 390=21.5$ cc. of $\mathrm{CO}_{2}$; 44.50 per cent $\times 390=173.5$ cc. of $\mathrm{O}_{2}$; and 50.0 per cent $\times 390=195$ cc. of $\mathrm{N}_{2}$.

There also remains in the pulmonary dead space $100 \mathrm{cc}$. of expired air of the above concentrations.

The next inspired air will contain 49.75 per cent $\mathrm{O}_{2}$, and 50.25 per cent of $\mathrm{N}_{2}$. The volume is $495 \mathrm{cc}$; only $395 \mathrm{cc}$. will, however, reach the alveolar spaces, as $100 \mathrm{cc}$. remains in the pul- 
monary dead space. Furthermore, the air, previously expired, and now present in this dead space, will be re-inhaled. Thus the oxygen that is inhaled into the alveolar spaces will be $44.5 \mathrm{cc}$. from the dead space, and 49.75 per cent $\times 395=$ $196.5 \mathrm{cc}$. from the inspired air. Similarly, the inhaled nitrogen will be $50.0+198.5 \mathrm{cc}$. The $\mathrm{CO}_{2}$ will be $119 \mathrm{cc}$., existing in the $2160 \mathrm{cc}$. of residual air $(5.50$ per cent $\times 2160=119)$, plus $5.5 \mathrm{cc}$. in the pulmonary dead space.

The total air mixture is now further changed by addition of $21.5 \mathrm{cc}$. of $\mathrm{CO}_{2}$, and removal of 26.5 cc. of $\mathrm{O}_{2}$, the amount of pulmonary gas exchange per breath.

After these various additions and subtractions, it is found that the pulmonary air contains $146 \mathrm{cc}$. of $\mathrm{CO}_{2}$ (5.50 per cent) ; 1176.5 cc. of $\mathrm{O}_{2}$ (44.4 per cent) ; and 1328.5 cc. of $\mathrm{N}_{2}$ (50.1 per cent).

Of this air mixture, $490 \mathrm{cc}$. are next exhaled, as already described.

If one carries out this procedure, breath by breath, for 13 breaths, results are obtained which are indicated in Table II.

TABLE II

Calculated "oxygen storage" effect, assuming complete mixture of gases. See text

\begin{tabular}{|c|c|c|c|c|c|c|c|c|c|c|}
\hline \multirow{2}{*}{$\begin{array}{l}\text { Breath } \\
\text { num- } \\
\text { ber }\end{array}$} & \multicolumn{4}{|c|}{ Inspired air } & \multicolumn{4}{|c|}{ Expired air } & \multirow{2}{*}{$\Delta \mathbf{N}_{2}$} & \multirow{2}{*}{ R.Q } \\
\hline & \multicolumn{2}{|c|}{ Oxygen } & \multicolumn{2}{|c|}{ Nitrogen } & \multicolumn{2}{|c|}{ Oxygen } & \multicolumn{2}{|c|}{ Nitrogen } & & \\
\hline & $\begin{array}{c}\text { per } \\
\text { cent }\end{array}$ & $c c$. & $\begin{array}{l}\text { per } \\
\text { cent }\end{array}$ & $c c$. & $\begin{array}{l}\text { per } \\
\text { cent }\end{array}$ & $c c$ & $\begin{array}{l}\text { per } \\
\text { cent }\end{array}$ & $c c$. & $\begin{array}{l}\text { per } \\
\text { cent }\end{array}$ & \\
\hline $\begin{array}{r}1 \\
3 \\
6 \\
10 \\
11 \\
13\end{array}$ & $\begin{array}{l}49.75 \\
49.25 \\
48.50 \\
47.50 \\
47.25 \\
46.75\end{array}$ & $\begin{array}{l}196.5 \\
194.5 \\
191.6 \\
187.6 \\
186.7 \\
184.7\end{array}$ & $\begin{array}{l}50.25 \\
50.75 \\
51.50 \\
52.50 \\
52.75 \\
53.25\end{array}$ & \begin{tabular}{|l|}
198.5 \\
200.5 \\
203.4 \\
207.4 \\
208.3 \\
210.3
\end{tabular} & \begin{tabular}{|l|}
44.4 \\
44.0 \\
43.4 \\
42.6 \\
42.4 \\
41.9
\end{tabular} & $\begin{array}{l}173.0 \\
171.9 \\
169.6 \\
166.1 \\
165.4 \\
163.4\end{array}$ & $\begin{array}{l}50.1 \\
50.5 \\
51.0 \\
51.9 \\
52.1 \\
52.6\end{array}$ & $\begin{array}{l}195.5 \\
196.6 \\
198.9 \\
202.4 \\
203.1 \\
205.0\end{array}$ & $\begin{array}{l}+0.1 \\
+0.2 \\
+0.5 \\
+0.6 \\
+0.7 \\
+0.7\end{array}$ & $\begin{array}{l}.91 \\
.95 \\
.98 \\
1.00 \\
1.01 \\
1.01\end{array}$ \\
\hline
\end{tabular}

It will be seen that after approximately 10 breaths, an equilibrium state is established, which maintains the expired nitrogen concentration approximately 0.7 per cent lower than the preceding inspired nitrogen concentration. The R.Q. is also in the region of 1.0. If similar calculations are carried out, but with constant, instead of decreasing, inspired oxygen concentration, then expired nitrogen is greater than inspired, and the R.Q. reaches and maintains its metabolic level of 0.81 .

The above calculation is, of course, based upon a schematic representation of pulmonary dead space and other functions, but is probably sufficiently accurate to indicate the general mechanism of the effect under consideration. Certain factors have also been omitted, as for example, nitrogen excretion from the lungs during the closed circuit breathing. This is considerable in total amount, but probably occurs chiefly during the first four or five minutes of the breathing period (5), and therefore should not greatly affect the equilibrium in the 6th, 7th and 8th minutes. The influence of water vapor pressure has also not been taken into account. The entire system is moist, and probably saturated, and as the temperature in inspiratory and expiratory tubes is nearly the same, this factor need not be considered for the immediate problem under discussion.

It is apparent from the above arguments, and from the experimental data, that in the breathing system which we have employed, with progressively decreasing inspired oxygen, equal mixture of an inert respired gas such as nitrogen not only does not exist but cannot exist, so long as there is even a partial mixture of inspired gases within the lungs and a sampling of the mixed gases in the expired air. We suggest that the constant $\mathrm{N}_{2} / \mathrm{H}_{2}$ ratio, found by Van Slyke and Binger (1) in their experiments, should be interpreted as indicating only an equilibrium state with respect to these gases in the various parts of the system, not an equality of concentration throughout all parts.

For purposes of simplification we have assumed in our calculations complete and even mixture of intrapulmonary gases. This is, of course, not strictly true, as shown by Siebeck (6) and more recently by Sonne (7). An approximate estimate of completeness of mixture can be obtained by comparing the $\mathrm{CO}_{2}$ and $\mathrm{O}_{2}$ concentrations of expired air $(B)$ samples with the concentrations in deep alveolar samples, taken a few seconds later. A correction is made for the gas exchange taking place during this time (usually about 5 seconds). Thus, if one takes the figures for the 8th minute expired air (Table I, $(B)$ sample), 5.4 per cent $\mathrm{CO}_{2}$ and 39.0 per cent oxygen, and uses an average value for functional residual air (for A.C.) of $2400 \mathrm{cc}$., the $\mathrm{CO}_{2}$ content of residual air will be $129.6 \mathrm{cc}$. In 5 seconds $\left(215 \mathrm{cc}\right.$. $\mathrm{CO}_{2}$ excreted per minute), $18 \mathrm{cc}$. of $\mathrm{CO}_{2}$ will be added, changing the $\mathrm{CO}_{2}$ concentration to $\frac{129.6+18}{2400}=6.2$ per cent. A similar calculation for oxygen 
H. C. A. LASSEN, A. COURNAND AND D. W. RICHARDS, JR.

changes this concentration from 39.0 to 38.1 per cent. Comparing these figures with the actual alveolar values of 6.2 per cent $\mathrm{CO}_{2}$ and 37.6 per cent $\mathrm{O}_{2}$, one infers that the distribution of $\mathrm{CO}_{2}$ through the expirable part of the functional residual air is good, in this subject; the oxygen somewhat diminished in concentration in the deep alveolar specimen. There is, however, no large discrepancy; and mixture of gases through alveolar spaces can therefore be considered fairly satisfactory, so far as distribution of nitrogen is concerned.

The question remains whether the principles of mixture which we have just outlined are sufficient to explain the entire discrepancy between expired nitrogen values with decreasing oxygen in inspired air, as compared with these values with constant or increasing inspired oxygen. Our calculations indicate that quantitatively these principles are sufficient to explain this discrepancy. Whether there are also in the human lungs other methods of mixing or distributing successive inspired breaths, cannot be determined from present data.

The practical value of the above considerations is their application to the determination of residual air. In normal individuals the nitrogen concentrations of the alveolar air samples (corrected) can be taken to represent, approximately, the average nitrogen concentrations throughout the residual air. If determinations of alveolar air are made, therefore, both before and at the end of the period of breathing through the closed circuit, and the nitrogen concentration of the air in the spirometer determined as in the manner prescribed by the method of Christie ( 3 ), then the functional residual air can readily be calculated by a slight modification of Christie's formula.

The principle of the equation is the same: nitrogen in system at the start $+65 \mathrm{cc}$. $=$ nitrogen in system at the end of the breathing period.

In the above equation, also, we have altered Christie's practice slightly, by including the 65 cc. of nitrogen excreted from the lungs during the period of rebreathing; rather than making a flat correction in the final value of the residual air.

The equation in detail is as follows:

$$
\text { (V) (Alv. } \bar{a})+(\text { D.S. })(.791)+65=(V) \text { (Alv. } \bar{p})
$$$$
\left.+\left(\text { D.S. }+\mathrm{O}_{2}\right) \text { (Spirom. } \mathrm{N}_{2}\right) \text {; }
$$

where

$V=$ volume of functional residual air, Alv. $\bar{a}=$ alveolar nitrogen concentration taken while A subject breathes room air,

Alv. $\bar{p}=$ alveolar nitrogen concentration taken immediately after end of breathing through closed circuit,

D.S. = volume of dead space of apparatus,

$\mathrm{O}_{2}=$ volume of excess oxygen in system at end of breathing period,

Spirom. $\mathrm{N}_{2}=$ concentration of nitrogen in spirometer at end of breathing period.

It is not actually necessary, for the purposes of this formula, to correct the alveolar samples for the number of seconds taken in obtaining them; inasmuch as the correction will be the same for each sample and will therefore cancel out as the equation is solved for $V$.

The above equation represents volumes at the temperature existing in the apparatus; after $V$ has been calculated, the actual volume of air in the lungs is then obtained by correcting for the increase due to the temperature $\left(37^{\circ} \mathrm{C}\right.$.) within the lungs; as has of course been described by Christie and others.

There is also a further small correction theoretically necessary due to the excess pressure of water vapor within the lungs (which must occupy some space). This pressure amounts to about $46 \mathrm{~mm}$. in the lungs, and about $25 \mathrm{~mm}$. in the apparatus at room temperature. The correction gives another slight increase to the figure for actual functional residual air; the ratio by which the calculated lung volume is multiplied being $\frac{760-25}{760-46}=1.02$. This correction in normal subjects amounts to only about $50 \mathrm{cc}$. and may be neglected.

The correction provided by the inclusion of values of actual alveolar air (or expired air), in the calculation of functional residual air, is not negligible, as will be seen from Table III (first two experiments). As also shown in Table III, we have been able to calculate, by a few simple modifications of the formula just given, the values of functional residual air for each of the 6, 7 and 8 minute breathing periods, in the closed circuit experiments described in the first part of this paper, with decreasing inspired oxygen concentrations. This was accomplished by making small corrections in $A$ - and $B$-sample values so as to make them approximately equal to spirometer and alveolar air values respectively. Since both $A$ and 
TABLE III

Values of functional residual air, calculated $(I)$ by assumption of equal mixture in breathing circuit, (II) by use of actual values of expired or alveolar air

\begin{tabular}{l|ll|c|c|c}
\hline \hline Subject* & \multicolumn{2}{|c|}{ Date } & $\begin{array}{c}\text { Number } \\
\text { of } \\
\text { minutes } \\
\text { breathing }\end{array}$ & $\begin{array}{c}\text { I } \\
\text { (Equal } \\
\text { mixture) }\end{array}$ & $\begin{array}{c}\text { II } \\
\text { (Actual } \\
\text { mixture) }\end{array}$ \\
\hline H. C. A. L. & February & 11,1935 & 7 & 3660 & 3410 \\
A. C...... & January & 24,1935 & 7 & 2380 & 2210 \\
A. C...... & November & 27,1935 & 6 & 2477 & 2278 \\
& & & 7 & 2659 & 2367 \\
A. C...... & December & 3,1935 & 8 & 2890 & 2438 \\
& & & 7 & 2540 & 2312 \\
D. R..... & January & 3,1936 & 8 & 2560 & 2309 \\
& & & 7 & 4300 & 2343 \\
& & 8 & 4960 & 3518 \\
& & & 8538 & 3538 \\
\hline
\end{tabular}

* Total pulmonary volume of Subject A. C. was 6200 cc., vital capacity $4500 \mathrm{cc}$; total pulmonary volume of Subject D. R. was 8100 cc.; vital capacity 5800 cc.

$B$, and alveolar air and spirometer values are obtained experimentally for the 8th minute, the necessary corrections for 6 th and 7 th minutes are easily made. ${ }^{2}$

It will be seen in Table III that the error due to assumption of equal mixture of nitrogen through the system is always appreciable, and may be considerable, in normal subjects. In Subject D. R., with large total capacity and large residual air, the excess in nitrogen concentration of inspired over expired air, after 6 to 8 minutes of breathing in the closed system, was about 1.3 per

2 The complete formula may be illustrated by the calculation of functional residual air for 7 minutes' breathing in the experiment of December 3,1935 (see Tables I and III) :

$.814 V+(1830)(.791)+65=(.531+.006) V$

$+(1830+2090-60)(.537+0.004)+60(.511)$;

$V=2190$ cc. (not corrected for temperature);

where

$1830=$ volume of dead space of apparatus,

$2090=$ volume of excess oxygen in system,

$.531+.006=B$ sample nitrogen concentration corrected so as to equal alveolar nitrogen concentration at 7 th minute,

$.537+.004=A$ sample nitrogen concentration corrected so as to equal spirometer nitrogen concentration at 7 th minute,

$60=$ volume removed from system when $A$ and $B$ samples are taken at end of 6 th minute of breathing,

(60) $(.511)=$ volume of nitrogen removed when $A$ and $B$ samples are taken at end of 6 th minute of breathing. cent, and the error due to the above assumption was therefore large.

\section{SUM MARY}

1. When a normal individual breathes for several minutes in a small closed circuit in which the oxygen concentration is steadily decreasing, an equilibrium state is reached and maintained, in which the expired nitrogen concentration is less than the inspired nitrogen concentration. This is due to the progressive increase in inspired nitrogen concentration with each breath, to mixing of inspired air in the lungs with air previously inhaled, and to the exhalation of mixed samples.

2 . In the determination of residual air volumes by quiet breathing, in a closed circuit apparatus, use of alveolar air samples, obtained before and at the end of the breathing period, enables a correction to be made for the inequality of concentrations of inert gases through the system. This correction may amount to several hundred cubic centimeters in normal subjects.

\section{BIBLIOGRAPHY}

1. Van Slyke, D. D., and Binger, C. A. L., The determination of lung volume without forced breathing. J. Exper. Med., 1923, 37, 457.

2. Anthony, A., Zur Methode der Spirometrie. Beitr. z. Klin. d. Tuberk., 1927, 67, 711.

3. Christie, R. V., The lung volume and its subdivisions. I. Methods of measurement. J. Clin. Invest., 1932, 11, 1099.

4. Sendroy, J., Jr., Hiller, A., and Van Slyke, D. D., Determination of lung volume by respiration of oxygen without forced breathing. J. Exper. Med., 1932, 55, 361.

5. Campbell, J. A., and Hill, L., Concerning the amount of nitrogen gas in the tissues and its removal by breathing almost pure oxygen. J. Physiol., 1931, 71, 309.

6. Siebeck, R., Uber den Gasaustausch zwischen der Aussenluft und den Alveolen. Ztschr. f. Biol., 1910, $55,267$.

II. Uber die Bedeutung und Bestimmung des schädlichen Raumes bei der Atmung. Skandinav. Arch. f. Physiol., 1911, 25, 81.

III. Die Lungenventilation beim Emphysem. Deutsches Arch. f. klin. Med., 1911, 102, 390.

7. Sonne, C., Der Respiratorische Luftaustausch in den Lungen. Ztschr. f. d. ges. exper. Med., 1934, 94, 13. 